03;09

\title{
Шумовые характеристики оптического отклика феррожидкостей на воздействие магнитного поля
}

\author{
(C) А.В. Прокофььев ${ }^{1}$, И.В. Плешаков ${ }^{1,2, \uparrow}$, M. Shlyagin ${ }^{3}$, П.М. Агрузов ${ }^{1}$, Е.Е. Бибик ${ }^{4}$, Ю.И. Кузьмин ${ }^{1}$ \\ ${ }^{1}$ Физико-технический институт им. А.Ф. Иоффре РАН, Санкт-Петербург, Россия \\ ${ }^{2}$ Санкт-Петербургский политехнический университет Петра Великого, Санкт-Петербург, Россия \\ ${ }^{3}$ Centro de Investigación Científica y Educación Superior de Ensenada, Ensenada, México \\ ${ }^{4}$ Санкт-Петербургский государственный технологический институт (Технический университет), Санкт-Петербург, Россия \\ ฯ E-mail: ivanple@yandex.ru
}

Поступило в Редакцию 22 февраля 2019г.

В окончательной редакции 19 марта 2019г.

Принято к публикации 29 апреля 2019г.

Исследован шум, создаваемый различными образцами феррожидкости при их зондировании волоконнооптическим методом. Показано, что включение магнитного поля приводит к его значительному увеличению, что предположительно связано с флуктуациями, сопровождающими процесс образования агрегатов. Экспериментально определены зависимости среднеквадратичного значения шума от напряженности поля и интенсивности зондирующего света. Обнаружено медленное снижение среднеквадратичного значения шума после выключения магнитного поля, отражающее релаксацию сформированных полем агрегатов.

Ключевые слова: магнитооптика, феррожидкости, оптоволокно, оптический шум.

DOI: 10.21883/PJTF.2019.15.48076.17745

Феррожидкости (магнитные жидкости), представляющие собой особого вида коллоидные растворы, являются объектом пристального внимания исследователей, прежде всего вследствие того, что они обладают необычными магнитными и гидродинамическими свойствами. Несмотря на то что эти вещества были подробно исследованы за несколько предшествующих десятилетий, они вновь вызвали значительный интерес в связи с появлением современных предложений по их использованию, например, в магнитоуправляемых элементах фотоники $[1,2]$, а также в некоторых важных биомедицинских приложениях $[3,4]$. Однако при наличии весьма большого числа работ, относящихся к оптическим явлениям в этих объектах, специальные исследования, посвященные их шумовым характеристикам, практически отсутствуют.

В настоящей работе, призванной частично восполнить данный пробел, изучалась шумовая составляющая сигнала, возбужденного светом, который подводился к образцу магнитной жидкости оптическим волокном. Похожие схемы используются в датчиках магнитного поля [5], переключателях [6], интерференционных решетках [7] и тому подобных приборах, т.е. нами моделировалась довольно распространенная оптоэлектронная система.

Феррожидкости являются коллоидами магнитоупорядоченных соединений с размерами частиц твердой фазы порядка $10 \mathrm{~nm}$, под действием поля группирующихся в протяженные агломераты, что и определяет специфику их магнитооптических характеристик. В экспериментах, выполненных нами, использовались образцы в виде растворов магнетита $\left(\mathrm{Fe}_{3} \mathrm{O}_{4}\right)$ в керосине или воде, изготовленные с помощью методов, основные принципы которых изложены в [8]. Когда растворителем был керосин, стабилизация системы, т.е. предотвращение слипания наночастиц, проводилась олеиновой кислотой. В водных растворах в качестве поверхностно-активного вещества применялись соли органических кислот щелочных металлов, образующие на частицах двойной гидрофильный слой, либо на поверхности частиц создавался двойной электрический слой, что достигалось увеличением кислотности среды (ионная стабилизация). Концентрация магнетита менялась в пределах 0.2-2 vol.\%.

Методика измерений состояла в том, что в образец через оптическое волокно подавался зондирующий свет, а отклик регистрировался в виде излучения, отраженного от торца волокна, т.е. от границы раздела стекло-жидкость. Его интенсивность, как известно, определяется соотношением коэффициентов преломления этих двух материалов. Поскольку у феррожидкости он зависит от характера взаимодействия света с ее структурными элементами (отдельными частицами или агломератами), откликом можно было управлять, изменяя магнитное поле, в которое помещался образец.

Схема установки показана на рис. 1. Источником света был суперлюминесцентный диод Superlum SLD 761 с широким спектром излучения и центральной длиной волны $\lambda=1.553 \mu \mathrm{m}$. Свет распространялся по кварцевому одномодовому волокну с диаметром моды $10 \mu \mathrm{m}$. Максимальная мощность источника излучения составляла $\sim 4 \mathrm{~mW}$, аттенюатор позволял регулировать интенсивность излучения на входе в образец (жидкость в ампуле), куда оно проходило через циркулятор. Отраженное излучение через циркулятор поступало на фотоприемник, а далее электронный сигнал подавался на многоканальный цифровой осциллограф и компьютер, 


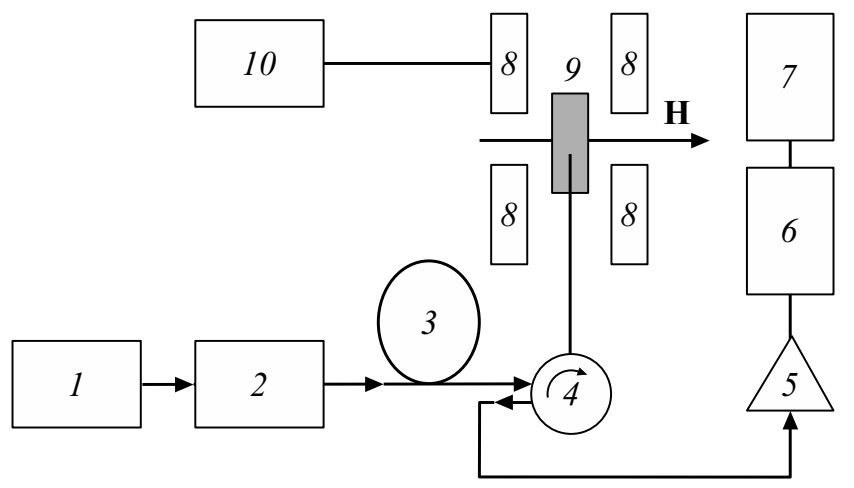

Рис. 1. Блок-схема установки. $1-$ суперлюминесцентный диод, 2 - аттенюатор, 3 - оптоволокно, 4 - циркулятор, 5 - фотоприемник, 6 - осциллограф, 7 - компьютер, 8 катушки Гельмгольца, 9 - образец, $10-$ источник питания.

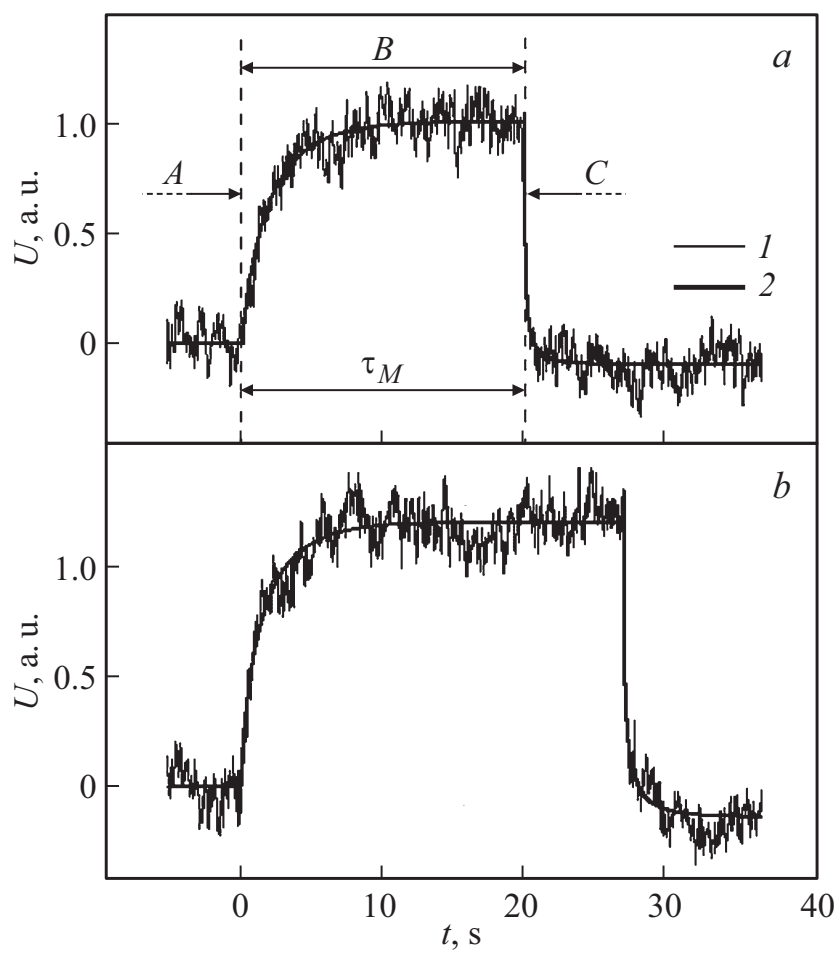

Рис. 2. Оптический отклик феррожидкости на основе керосина с концентрацией твердой фазы 1 vol.\% при различных амплитудах и длительностях импульса магнитного поля. $1-$ сигнал, $2-$ подгоночная функция. $a-H=100 \mathrm{Oe}, \tau_{M}=20 \mathrm{~s}$; $b-H=130 \mathrm{Oe}, \tau_{M}=27 \mathrm{~s}$.

где одновременно могли отображаться магнитное поле и оптический отклик. Магнитное поле, создаваемое катушками Гельмгольца, прикладывалось перпендикулярно направлению распространения света. Его напряженность $H$ перестраивалась в пределах $0-800$ Ое. Катушки питались от стабилизированного источника тока.

Результаты, полученные на всех образцах, оказались качественно похожими, хотя наиболее интенсивный сигнал наблюдался от феррожидкости на основе керосина (в качестве примера он представлен на рис. 2). В экспериментах на освещенный образец в определенный момент времени подавалось магнитное поле, которое затем выключалось. На протяжении действия этого импульса развивался оптический отклик, содержащий шумовую составляющую, хорошо видную на приведенных осциллограммах. Как при увеличении поля, так и при увеличении мощности засветки амплитуда отклика и среднеквадратичное значение шума возрастали.

Предметом дальнейшего анализа являлась шумовая компонента отклика. Сначала было проверено, что источником шума является именно феррожидкость. Для этого отдельно изучались шумы оптического излучения и фотоприемника, а также те случайные изменения магнитного поля, которые могли быть вызваны флуктуациями тока, питающего катушки. Было установлено, что в каждом из этих трактов среднеквадратичное значение шумового напряжения на один-два порядка ниже появляющегося при включении в систему образца. Кроме того, различались и другие характеристики указанных процессов: по предварительным данным спектр флуктуаций оптического отклика феррожидкости близок к $1 / f$-шуму.

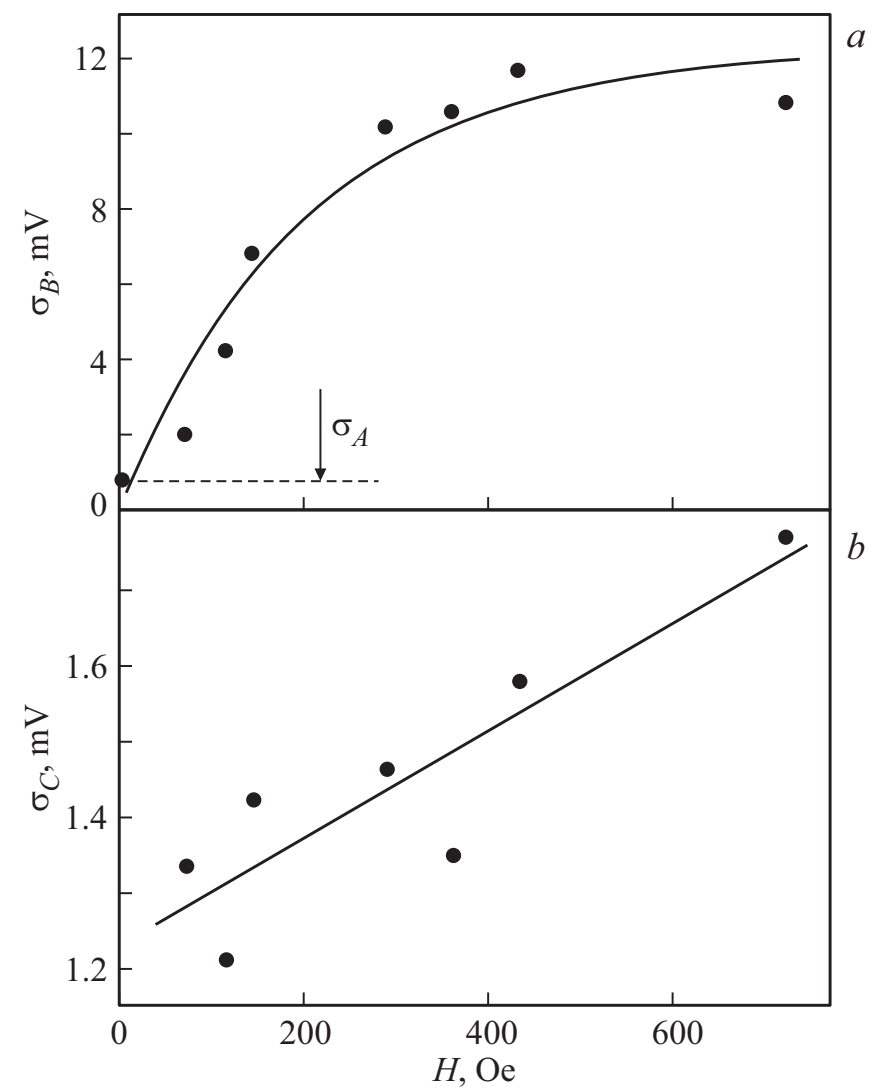

Рис. 3. Среднеквадратичные отклонения шумовой составляющей оптического отклика водной ионно-стабилизированной феррожидкости с концентрацией твердой фазы 0.35 vol.\% во время $(a)$ и после $(b)$ действия импульса магнитного поля (значения $\sigma_{C}$ определялись на интервале длительностью $2 \mathrm{~s}$ сразу после выключения импульса). 
Процедура разделения случайной $X(t)$ и детерминированной $S(t)$ частей сигнала проводилась следующим образом. Для аппроксимации $S(t)$ выбиралась подгоночная функция, наилучшим (с точки зрения параметров регрессии) образом описывающая отклик, и далее она вычиталась из полного сигнала. Таким образом, оставалась только его шумовая составляющая, т. е. использовалась предполагаемая аддитивность шума. Из опробованных вариантов $S(t)$ самой подходящей оказалась растянутая экспонента:

$$
\begin{gathered}
S(t)=S_{0}\left\{1-\exp \left[-\left(t / \tau_{A}\right)^{\beta}\right]\right\}, \\
S(t)=S_{0} \exp \left\{-\left[\left(t-\tau_{M}\right) / \tau_{B}\right]^{\beta}\right\} .
\end{gathered}
$$

Уравнение (1a) описывает поведение сигнала при включенном поле, уравнение $(1 \mathrm{~b})-$ его спад. Здесь $S_{0}-$ aмплитуда, $\tau_{A}$ и $\tau_{B}-$ характерные времена нарастания сигнала и его релаксации, $\tau_{M}$ - длительность магнитного импульса, а $\beta$ - показатель, обычно несколько меньший единицы. Помимо формального соответствия хорошим условиям подгонки выражения (1) имеют определенный физический смысл как функции, часто применяющиеся при феноменологическом описании неупорядоченных систем. Качество совпадения $S(t)$ с данными эксперимента демонстрирует рис. 2.

Значения статистических параметров процесса $X(t)$ до, во время и после включения магнитного поля различались (на рис. 2 эти интервалы обозначены как $A, B$ и $C)$. После вычитания на каждом из участков вычислялись среднеквадратичные отклонения $\left(\sigma_{A}, \sigma_{B}\right.$ и $\sigma_{C}$ соответственно). На интервалах $A$ и $C$ значения $\sigma$ определялись на смещаемых сегментах с длительностями $1-2 \mathrm{~s}$.

На рис. 3 показаны зависимости $\sigma_{B}$ и $\sigma_{C}$ от $H$ для образца водной ионно-стабилизированной феррожидкости. Особенностью данного случая является то, что в таких образцах амплитуда отклика оказывается очень слабой, а шум возрастает, что отражает отмеченную нами закономерность, относящуюся к формированию агломератов (было установлено, что легче всего оно происходит в керосиновых растворах, затрудненно в водных растворах, стабилизированных поверхностноактивными веществами, и хуже всего идет в материалах с ионной стабилизацией).

Поскольку в основе механизма возникновения сигнала лежит разность показателей преломления материала оптоволокна и жидкости, флуктуации, связанные с движением частиц в образце, должны порождать шум в оптическом отклике. Из рис. 3, $a$ видно, что он возрастает при включении поля, инициирующего процесс агрегирования, который сопровождается как изменением показателя преломления, так и усилением флуктуаций (можно отметить, что зависимость $\sigma_{B}(H)$ коррелирует с кривой намагничивания феррожидкости). Данное предположение подтверждается тем, что среднеквадратичное значение шума на участке $C$ сразу после импульса поля, т.е. там, где продолжает существовать релаксирующая к исходному состоянию магнитная структура, выше, чем на участке $A$ (рис. $3, b)$. В согласии с ним находится также экспериментально наблюдавшаяся нарастающая зависимость $\sigma_{B}$ и $\sigma_{C}$ от интенсивности света.

Выполненное нами исследование продемонстрировало важность учета шумовых характеристик феррожидкостей при их возможном использовании в оптических устройствах и показало их связь с магнитными параметрами этих материалов. Можно предположить, что изучение деталей поведения шума окажется полезным для уточнения свойств таких сред.

\section{Благодарности}

Авторы благодарят К.Г. Гареева за предоставление ионно-стабилизированной феррожидкости.

\section{Финансирование работы}

M. Shlyagin благодарит CONACYT (Mexico) за грант 613204-454957, поддержавший его пребывание в ФТИ им. А.Ф. Иоффе РАН.

\section{Конфликт интересов}

Авторы заявляют, что у них нет конфликта интересов.

\section{Список литературы}

[1] Layeghi A., Latifi H. // J. Lightwave Technol. 2018. V. 36. N 4. P. 1097-1104.

[2] Pathak S., Jain K., Noorjahan, Kumar V., Pant R.P. // IEEE Sens. J. 2017. V. 17. N 9. P. 2670-2675.

[3] Iszály Zs., Lovász K., Nagy I., Márián I.G., Rácz J., Szabó I.A., Tóth L., Vas N.F., Vékony V., Nándori I. // J. Magn. Magn. Mater. 2018. V. 466. P. 452-462.

[4] Lyutyy T.V., Hryshko O.M., Yakovenko M.Yu. // J. Magn. Magn. Mater. 2019. V. 473. P. 198-204.

[5] Li Z., Liao C., Song J., Wang Y., Zhu F., Wang Y., Dong X. // Photon. Res. 2016. V. 4. N 5. P. 197-201.

[6] Dai Q.-F., Deng H.-D., Zhao W.-R., Liu J., Wu L.-J., Lan S., Gopa A.V. // Opt. Lett. 2010. V. 35. N 2. P. 97-99.

[7] Miao Y., Zhang K., Liu B., Lin W., Zhang H., Lu Y., Yao J. // IEEE Photon. Technol. Lett. 2013. V. 25. N 3. P. 306-309.

[8] Gribanov N.M., Bibik E.E., Buzunov O.V., Naumov V.N. // J. Magn. Magn. Mater. 1990. V. 85. P. 7-10 